\title{
On Fixed Point theorems in Fuzzy Metric Spaces
}

\author{
Shailesh T.Patel ,Ramakant Bhardwaj*,Rakesh Shrivastava**,Shyam Patkar*,Sanjay Choudhary*** \\ The Research Scholar of Singhania University, Pacheri Bari (Jhunjhunu) \\ *Truba Institutions of Engineering \& I.T. Bhopal, (M.P.) \\ **JNCT, Bhopal. \\ ***Prof.\&Head Deptt.of Mathematics Govt.NMV Hoshangabad.
}

\begin{abstract}
This paper presents some common fixed point theorems for occasionally weakly compatible mappings in fuzzy metric spaces.
\end{abstract}

Keywords: Occasionally weakly compatible mappings,fuzzy metric space.

\section{Introduction}

Fuzzy set was defined by Zadeh [7]. Kramosil and Michalek [5] introduced fuzzy metric space, George and Veermani [2] modified the notion of fuzzy metric spaces with the help of continuous t-norms. Many researchers have obtained common fixed point theorems for mappings satisfying different types.introduced the new concept continuous mappings and established some common fixed point theorems.open problem on the existence of contractive definition which generates a fixed point but does not force the mappings to be continuous at the fixed point.this paper presents some common fixed point theorems for more general .

\section{Preliminary Notes}

Definition 2.1 [7] A fuzzy set $A$ in $X$ is a function with domain $X$ and values in $[0,1]$.

Definition $2.2[6]$ A binary operation $*:[0,1] \times[0,1] \rightarrow[0,1]$ is a continuous t-norms if $*$ is satisfying conditions:

(1) $*$ is an commutative and associative;

(2) * is continuous;

(3) $\mathrm{a} * 1=\mathrm{a}$ forall $\mathrm{a} \in[0,1]$;

(4) $\mathrm{a} * \mathrm{~b} \leq \mathrm{c} * \mathrm{~d}$ whenever $\mathrm{a} \leq \mathrm{c}$ and $\mathrm{b} \leq \mathrm{d}$, and a,b,c,d $\in[0,1]$.

Definition 2.3 [2] A 3-tuple $(\mathrm{X}, \mathrm{M}, *)$ is said to be a fuzzy metric space if $\mathrm{X}$ is an arbitrary set, $*$ is a continuous tnorm and $\mathrm{M}$ is a fuzzy set on $\mathrm{X}^{2} \times(0, \infty)$ satisfying the following conditions, for all $\mathrm{x}, \mathrm{y}, \mathrm{z} \in \mathrm{X}, \mathrm{s}, \mathrm{t}>0$,

(fl) $\mathrm{M}(\mathrm{x}, \mathrm{y}, \mathrm{t})>0$;

$(\mathrm{f} 2) \mathrm{M}(\mathrm{x}, \mathrm{y}, \mathrm{t})=1$ if and only if $\mathrm{x}=\mathrm{y}$;

$\left(\mathrm{f}_{3}\right) \mathrm{M}(\mathrm{x}, \mathrm{y}, \mathrm{t})=\mathrm{M}(\mathrm{y}, \mathrm{x}, \mathrm{t})$

$\left(\mathrm{f}_{4}\right) \mathrm{M}(\mathrm{x}, \mathrm{y}, \mathrm{t}) * \mathrm{M}(\mathrm{y}, \mathrm{z}, \mathrm{s}) \leq \mathrm{M}(\mathrm{x}, \mathrm{z}, \mathrm{t}+\mathrm{s})$;

$\left(\mathrm{f}_{5}\right) \mathrm{M}(\mathrm{x}, \mathrm{y}, \mathrm{)}):(0, \infty) \rightarrow(0,1]$ is continuous.

Then $\mathrm{M}$ is called a fuzzy metric on $\mathrm{X}$.Then $\mathrm{M}(\mathrm{x}, \mathrm{y}, \mathrm{t})$ denotes the degree of nearness between $\mathrm{x}$ and $\mathrm{y}$ with respect to t.

Definition 2.4[2]Let $(X, d)$ be a metric space.Denotea $* b=a b$ for all $a, b \in[0,1]$ and $M_{d}$ be fuzzy sets on $X^{2} \times(0, \infty)$ defined as follows:

$$
\mathrm{M}_{\mathrm{d}}(\mathrm{x}, \mathrm{y}, \mathrm{t})=\frac{t}{t+d(x, y)} .
$$

Then $\left(\mathrm{X}, \mathrm{M}_{\mathrm{d}}, *\right)$ is a fuzzy metric space.Wecall this fuzzy metric induced by a metric $\mathrm{d}$ as the standard intuitionistic fuzzy metric.

Definition 2.5[2]Let $(X, M, *)$ is a fuzzy metric space.Then

(a) a sequence $\left\{\mathrm{x}_{\mathrm{n}}\right\}$ in $\mathrm{X}$ is said to convers to $\mathrm{x}$ in $\mathrm{X}$ if for each $\mathrm{\epsilon}>\mathrm{o}$ and each $\mathrm{t}>\mathrm{o}, \exists n_{o} \in N$ such

That $\mathrm{M}\left(\mathrm{x}_{\mathrm{n}}, \mathrm{x}, \mathrm{t}\right)>1-\mathrm{e}$ for all $\mathrm{n} \geq \mathrm{n}_{\mathrm{o}}$.

(b)a sequence $\left\{\mathrm{x}_{\mathrm{n}}\right\}$ in $\mathrm{X}$ is said to cauchy to if for each $\epsilon>0$ and each $\mathrm{t}>0, \exists n_{o} \in N$ such

That $M\left(x_{n}, x_{m}, t\right)>1-\epsilon$ for all $n, m \geq n_{\text {o. }}$

(c) A fuzzy metric space in which euery Cauchy sequence is convergent is said to be complete.Definition 2.6[3]

Two self mappings $\mathrm{f}$ and $\mathrm{g}$ of a fuzzy metric space $(\mathrm{X}, \mathrm{M}, *)$ are called compatible if

$\lim _{n \rightarrow \infty} M\left(f g x_{n}, g f x_{n}, t\right)=1$ whenever $\left\{\mathrm{x}_{\mathrm{n}}\right\}$ is a sequencein $\mathrm{X}$ such that $\lim _{n \rightarrow \infty} f x_{n}=\lim _{n \rightarrow \infty} g x_{n}=x$

For some $\mathrm{x}$ in $\mathrm{X}$.

Definition 2.7[1]Twoself mappings $\mathrm{f}$ and $\mathrm{g}$ of a fuzzy metric space $\left(\mathrm{X}, \mathrm{M},{ }^{*}\right)$ are called reciprocally continuous on $\mathrm{X}$ if $\lim _{n \rightarrow \infty} f g x_{n}=f x$ and $\lim _{n \rightarrow \infty} g f x_{n}=g x$ whenever $\left\{\mathrm{x}_{\mathrm{n}}\right\}$ is a sequence in $\mathrm{X}$ such that $\lim _{n \rightarrow \infty} f x_{n}=\lim _{n \rightarrow \infty} g x_{n}=x$ for some $\mathrm{x}$ in $\mathrm{X}$. 
Lemma 2.8[4] Let $X$ be a set, f,gowcself maps of $X$. If $f$ and $g$ have a unique point of coincidence, $w=f x=g x$, then $\mathrm{w}$ is the unique common fixed point of $\mathrm{f}$ and $\mathrm{g}$.

\section{Main Results}

Theorem 3.1Let $(X, M, *)$ be a complete fuzzy metric space and let $P, R, S$ and $T$ be self-mappings of $X$. Let the pairs $\{\mathrm{P}, \mathrm{S}\}$ and $\{\mathrm{R}, \mathrm{T}\}$ be owc.If there exists $\mathrm{q} \epsilon(0,1)$ such that

$M(P x, R y . q t)$

$$
\int_{0} \xi(t) d t
$$

$M(P x, R y, q t) \geq \min \{M(S x, T y, t), M(S x, P x, t), M(R y, T y, t), M(P x, T y, t), M(R y, S x, t)$,

$$
\mathrm{M}(\mathrm{Px}, \mathrm{Ry}, \mathrm{t}), \mathrm{M}(\mathrm{Sx}, \mathrm{Ty}, \mathrm{t}) * \mathrm{M}(\mathrm{Px}, \mathrm{Px}, \mathrm{t})\} \quad \ldots \ldots \ldots \ldots . . .(1)
$$

For all $\mathrm{x}, \mathrm{y} \epsilon \mathrm{X}$ and for all $\mathrm{t}>\mathrm{o}$, then there exists a unique point $\mathrm{w} \epsilon \mathrm{X}$ such that $\mathrm{Pw}=\mathrm{Sw}=\mathrm{w}$ and a unique point $\mathrm{z} \epsilon \mathrm{X}$ such that $\mathrm{Rz}=\mathrm{Tz}=\mathrm{z}$. Moreover $\mathrm{z}=\mathrm{w}$ so that there is a unique common fixed point of $\mathrm{P}, \mathrm{R}, \mathrm{S}$ and $\mathrm{T}$.

Proof :Let the pairs $\{P, S\}$ and $\{R, T\}$ be owc, so there are points $x, y \in X$ such that $P x=S x$ andRy=Ty. We claim thatPx=Ry. If not, by inequality (1)

$$
\begin{aligned}
& M(P x, R y, q t) \geq \min \{M(S x, T y, t), M(S x, P x, t), M(R y, T y, t), M(P x, T y, t), M(R y, S x, t), \\
&M(P x, R y, t), M(S x, T y, t) * M(P x, P x, t)\} \\
& M(P x, R y, q t) \geq \min \{M(P x, R y, t), M(P x, P x, t), M(T y, T y, t), M(P x, R y, t), M(R y, P x, t), \\
&M(P x, R y, t), M(P x, R y, t) * M(P x, P x, t)\} \\
& \geqM(P x, R y, t), M(P x, R y, t), M(P x, R y, t) * 1\} \\
& M(P x, P x, t), \quad M(T y, T y, t), \quad M(P x, R y, t), \\
&= M(P x, R y, t) .
\end{aligned}
$$

Therefore $\mathrm{Px}=\mathrm{Ry}$, i.e. $\mathrm{Px}=\mathrm{Sx}=\mathrm{Ry}=$ Ty. Suppose that there is a another point $\mathrm{z}$ such that $\mathrm{Pz}=\mathrm{Sz}$ then by (1) we have $\mathrm{Pz}=\mathrm{Sz}=\mathrm{Ry}=\mathrm{Ty}$, so $\mathrm{Px}=\mathrm{Pz}$ and $\mathrm{w}=\mathrm{Px}=\mathrm{Sx}$ is the unique point of coincidence of $\mathrm{P}$ and $\mathrm{S}$.By Lemma $2.8 \mathrm{w}$ is the only common fixed point of $\mathrm{P}$ and $\mathrm{S}$. Similarly there is a unique point $\mathrm{z} \in \mathrm{X}$ such that $\mathrm{z}=\mathrm{Rz}=$ Tz.

Assume that $\mathrm{w} \neq \mathrm{z}$. we have

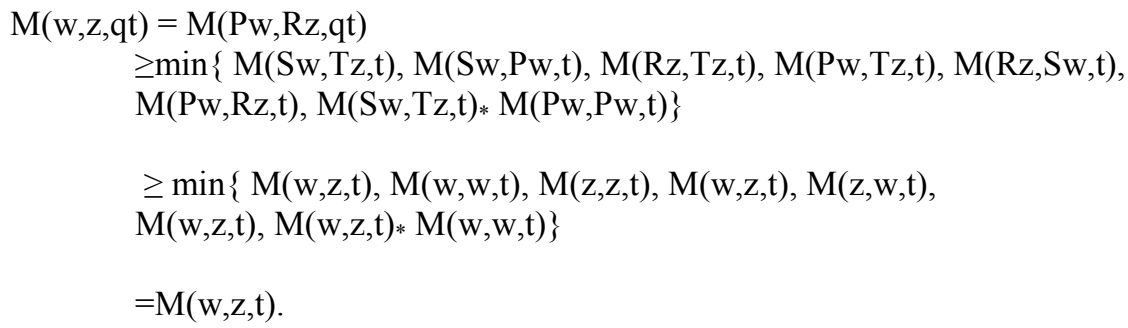

Therefore we have $z=w$ and $z$ is a common fixed point of $P, R, S$ and $T$. The uniqueness of the fixed point holds. Theorem 3.2 Let $(X, M, *)$ be a complete fuzzy metric space and let $P, R, S$ and $T$ be self-mappings of $X$. Let the pairs $\{\mathrm{P}, \mathrm{S}\}$ and $\{\mathrm{R}, \mathrm{T}\}$ be owc.If there exists $\mathrm{q} \epsilon(0,1)$ such that

$$
\begin{array}{r}
M(P x, R y, q t) \geq \varnothing(\min \{M(S x, T y, t), M(S x, P x, t), M(R y, T y, t), M(P x, T y, t), M(R y, S x, t), \\
M(P x, R y, t), M(S x, T y, t) * M(P x, P x, t)\})
\end{array}
$$

For all $\mathrm{x}, \mathrm{y} \epsilon$ Xand $\varnothing:[0,1] \rightarrow[0,1]$ such that $\varnothing(\mathrm{t})>\mathrm{t}$ for all $0<\mathrm{t}<1$, then there existsa unique common fixed point of $\mathrm{P}, \mathrm{R}, \mathrm{S}$ and $\mathrm{T}$.

Proof :Let the pairs $\{P, S\}$ and $\{R, T\}$ be owc, so there are points $x, y \in X$ such that $P x=S x$ and $R y=T y$. We claim that $\mathrm{Px}=\mathrm{Ry}$. If not, by inequality (2)

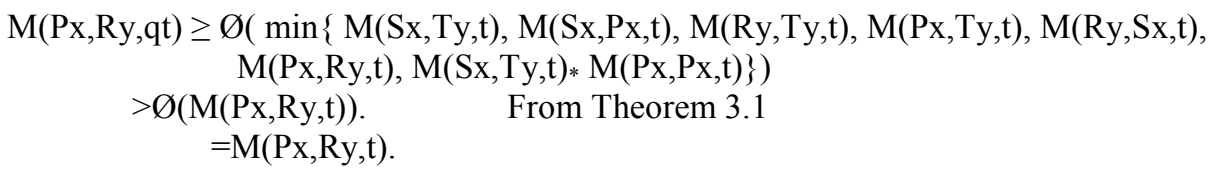

Assume that $\mathrm{w} \neq \mathrm{z}$. we have

$\mathrm{M}(\mathrm{w}, \mathrm{z}, \mathrm{qt})=\mathrm{M}(\mathrm{Pw}, \mathrm{Rz}, \mathrm{qt})$

$\geq \min \{\mathrm{M}(\mathrm{Sw}, \mathrm{Tz}, \mathrm{t}), \mathrm{M}(\mathrm{Sw}, \mathrm{Pw}, \mathrm{t}), \mathrm{M}(\mathrm{Rz}, \mathrm{Tz}, \mathrm{t}), \mathrm{M}(\mathrm{Pw}, \mathrm{Tz}, \mathrm{t}), \mathrm{M}(\mathrm{Rz}, \mathrm{Sw}, \mathrm{t})$, 


$$
\begin{array}{ll}
\mathrm{M}(\mathrm{Pw}, \mathrm{Rz}, \mathrm{t}), \mathrm{M}(\mathrm{Sw}, \mathrm{Tz}, \mathrm{t}) * \mathrm{M}(\mathrm{Pw}, \mathrm{Pw}, \mathrm{t})\} \\
=\mathrm{M}(\mathrm{w}, \mathrm{z}, \mathrm{t}) . & \text { From Theorem } 3.1
\end{array}
$$

Therefore we have $\mathrm{z}=\mathrm{w}$ and $\mathrm{z}$ is a common fixed point of $\mathrm{P}, \mathrm{R}, \mathrm{S}$ and $\mathrm{T}$. The uniqueness of the fixed point holds. Theorem 3.3 Let $(X, M, *)$ be a complete fuzzy metric space and let $P, R, S$ and $T$ be self-mappings of $X$. Let the pairs $\{\mathrm{P}, \mathrm{S}\}$ and $\{\mathrm{R}, \mathrm{T}\}$ be owc.If there exists $\mathrm{q} \epsilon(0,1)$ such that

$$
\begin{array}{r}
M(P x, R y, q t) \geq \varnothing(M(S x, T y, t), M(S x, P x, t), M(R y, T y, t), M(P x, T y, t), M(R y, S x, t), \\
M(P x, R y, t), M(S x, T y, t) * M(P x, P x, t))
\end{array}
$$

For all $\mathrm{x}, \mathrm{y \epsilon X}$ and $\varnothing:[0,1]^{7} \rightarrow[0,1]$ such that $\varnothing(\mathrm{t}, 1,1, \mathrm{t}, \mathrm{t}, 1, \mathrm{t})>\mathrm{t}$ for all $0<\mathrm{t}<1$, then there exists a unique common fixed point of $\mathrm{P}, \mathrm{R}, \mathrm{S}$ and $\mathrm{T}$.

Proof: Let the pairs $\{P, S\}$ and $\{R, T\}$ be owc, so there are points $x, y \in X$ such that $P x=S x$ and $R y=T y$. We claim that $\mathrm{Px}=\mathrm{Ry}$. If not, by inequality (3)

$$
\begin{aligned}
& M(P x, R y, q t) \geq \varnothing(M(S x, T y, t), M(S x, P x, t), M(R y, T y, t), M(P x, T y, t), M(R y, S x, t), \\
& \mathrm{M}(\mathrm{Px}, \mathrm{Ry}, \mathrm{t}), \mathrm{M}(\mathrm{Sx}, \mathrm{Ty}, \mathrm{t}) * \mathrm{M}(\mathrm{Px}, \mathrm{Px}, \mathrm{t})) \\
& M(P x, R y, q t) \geq \varnothing(M(P x, R y, t), M(P x, P x, t), M(T y, T y, t), M(P x, R y, t), M(R y, P x, t), \\
& \mathrm{M}(\mathrm{Px}, \mathrm{Ry}, \mathrm{t}), \mathrm{M}(\mathrm{Px}, \mathrm{Ry}, \mathrm{t}) * \mathrm{M}(\mathrm{Px}, \mathrm{Px}, \mathrm{t})) \\
& =\quad \varnothing(\mathrm{M}(\mathrm{Px}, \mathrm{Ry}, \mathrm{t}), \quad \mathrm{M}(\mathrm{Px}, \mathrm{Px}, \mathrm{t}), \quad \mathrm{M}(\mathrm{Ty}, \mathrm{Ty}, \mathrm{t}), \quad \mathrm{M}(\mathrm{Px}, \mathrm{Ry}, \mathrm{t}), \\
& \mathrm{M}(\mathrm{Px}, \mathrm{Ry}, \mathrm{t}), \mathrm{M}(\mathrm{Px}, \mathrm{Ry}, \mathrm{t}), \mathrm{M}(\mathrm{Px}, \mathrm{Ry}, \mathrm{t}) * 1) \\
& =\varnothing(M(P x, R y, t), 1,1, M(P x, R y, t), M(P x, R y, t), M(P x, R y, t), M(P x, R y, t)) \\
& >\mathrm{M}(\mathrm{Px}, \mathrm{Ry}, \mathrm{t}) \text {. }
\end{aligned}
$$

A contradiction, therefore $\mathrm{Px}=\mathrm{Ry}$, i.e. $\mathrm{Px}=\mathrm{Sx}=\mathrm{Ry}=\mathrm{Ty}$. Suppose that there is a another point $\mathrm{z}$ such that $\mathrm{Pz}=$ Sz then by (3) we have $\mathrm{Pz}=\mathrm{Sz}=\mathrm{Ry}=\mathrm{Ty}$, so $\mathrm{Px}=\mathrm{Pz}$ and $\mathrm{w}=\mathrm{Px}=\mathrm{Sx}$ is the unique point of coincidence of $\mathrm{P}$ and S.By Lemma $2.8 \mathrm{w}$ is the only common fixed point of $\mathrm{P}$ and S.Similarly there is a unique point $z \in X$ such that $\mathrm{z}=\mathrm{Rz}=\mathrm{Tz}$. Thus $\mathrm{z}$ is a common fixed point of $\mathrm{P}, \mathrm{R}, \mathrm{S}$ and $\mathrm{T}$. The uniqueness of the fixed point holds from (3).

Theorem 3.4 Let $(\mathrm{X}, \mathrm{M}, *)$ be a complete fuzzy metric space and let $\mathrm{P}, \mathrm{R}, \mathrm{S}$ and $\mathrm{T}$ be self-mappings of $\mathrm{X}$. Let the pairs $\{P, S\}$ and $\{R, T\}$ be owc.If there exists $q \epsilon(0,1)$ for all $x, y \in X$ and $t>0$

$$
\begin{aligned}
& \mathrm{M}(\mathrm{Px}, \mathrm{Ry}, \mathrm{qt}) \geq \mathrm{M}(\mathrm{Sx}, \mathrm{Ty}, \mathrm{t}) * \mathrm{M}(\mathrm{Sx}, \mathrm{Px}, \mathrm{t}) * \mathrm{M}(\mathrm{Ry}, \mathrm{Ty}, \mathrm{t}) * \mathrm{M}(\mathrm{Px}, \mathrm{Ty}, \mathrm{t}) * \mathrm{M}(\mathrm{Ry}, \mathrm{Sx}, \mathrm{t}) * \\
& \mathrm{M}(\mathrm{Px}, \mathrm{Ry}, \mathrm{t}) * \mathrm{M}(\mathrm{Sx}, \mathrm{Ty}, \mathrm{t})
\end{aligned}
$$

Then there existsa unique common fixed point of $\mathrm{P}, \mathrm{R}, \mathrm{S}$ and $\mathrm{T}$.

Proof: Let the pairs $\{\mathrm{P}, \mathrm{S}\}$ and $\{\mathrm{R}, \mathrm{T}\}$ be owc, so there are points $\mathrm{x}, \mathrm{y} \in \mathrm{X}$ such that $\mathrm{Px}=\mathrm{Sx}$ and $\mathrm{Ry}=\mathrm{Ty}$. We claim that $\mathrm{Px}=\mathrm{Ry}$. If not, by inequality (4)

We have

$$
\begin{aligned}
M(P x, R y, q t) \geq M(S x, T y, t) * M(S x, P x, t) * M(R y, T y, t) * M(P x, T y, t) * M(R y, S x, t) * \\
M(P x, R y, t) * M(S x, T y, t) \\
=M(P x, R y, t) * M(P x, P x, t) * M(T y, T y, t) * M(P x, R y, t) * M(R y, P x, t) * \\
M(P x, R y, t) * M(P x, R y, t) \\
=M(P x, R y, t) * 1 * 1 * M(P x, R y, t) * M(R y, P x, t) * \\
M(P x, R y, t) * M(P x, R y, t) \\
>M(P x, R y, t) .
\end{aligned}
$$

Thus we have $\mathrm{Px}=\mathrm{Ry}$, i.e. $\mathrm{Px}=\mathrm{Sx}=\mathrm{Ry}=\mathrm{Ty}$. Suppose that there is a another point $\mathrm{z}$ such that $\mathrm{Pz}=\mathrm{Sz}$ then by (4) we have $\mathrm{Pz}=\mathrm{Sz}=\mathrm{Ry}=\mathrm{Ty}$, so $\mathrm{Px}=\mathrm{Pz}$ and $\mathrm{w}=\mathrm{Px}=\mathrm{Sx}$ is the unique point of coincidence of $\mathrm{P}$ and S.Similarly there is a unique point $z \in X$ such that $z=R z=T z$. Thus $w$ is a common fixed point of $P, R, S$ and $T$.

Corollary 3.5 Let $(X, M, *)$ be a complete fuzzy metric space and let $\mathrm{P}, \mathrm{R}, \mathrm{S}$ and $\mathrm{T}$ be self-mappings of $\mathrm{X}$. Let the pairs $\{P, S\}$ and $\{R, T\}$ be owc.If there exists $q \epsilon(0,1)$ for all $x, y \in X$ and $t>0$

$$
\begin{array}{r}
M(P x, R y, q t) \geq M(S x, T y, t) * M(S x, P x, t) * M(R y, T y, t) * M(P x, T y, t) * M(R y, S x, 2 t) * \\
M(P x, R y, t) * M(S x, T y, t) \quad \ldots \ldots \ldots \ldots \ldots \ldots . . .(5)
\end{array}
$$

Then there existsa unique common fixed point of $P, R, S$ and $T$.

Proof: We have

$$
\begin{aligned}
M(P x, R y, q t) \geq & M(S x, T y, t) * M(S x, P x, t) * M(R y, T y, t) * M(P x, T y, t) * M(R y, S x, 2 t) * \\
& M(P x, R y, t) * M(S x, T y, t) \\
\geq & M(S x, T y, t) * \quad M(S x, P x, t) * M(R y, T y, t) * \quad M(P x, T y, t) * \quad M(S x, T y, t) * \quad M \quad M(T y, R y, t) * \\
& M(P x, R y, t) * M(S x, T y, t) \\
\geq & M(S x, T y, t) * M(S x, P x, t) * M(R y, T y, t) * M(P x, T y, t) * M(P x, R y, t) *
\end{aligned}
$$




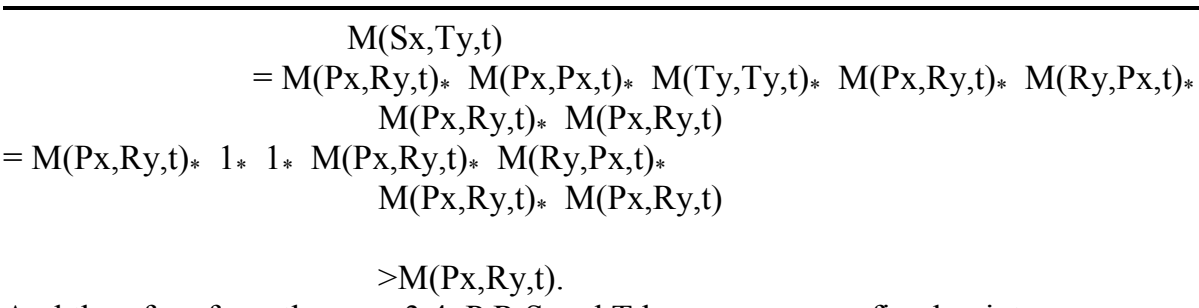

And therefore from theorem 3.4, P,R,S and T have a common fixed point.

Corollary 3.6 Let $(X, M, *)$ be a complete fuzzy metric space and let $\mathrm{P}, \mathrm{R}, \mathrm{S}$ and $\mathrm{T}$ be self-mappings of $\mathrm{X}$. Let the pairs $\{P, S\}$ and $\{R, T\}$ be owc.If there exists $q \epsilon(0,1)$ for all $x, y \in X$ and $t>0$

$$
M(P x, R y, q t) \geq M(S x, T y, t)
$$

Then there existsa unique common fixed point of $\mathrm{P}, \mathrm{R}, \mathrm{S}$ and $\mathrm{T}$.

Proof: The Proof follows from Corollary 3.5

Theorem 3.7 Let $\left(X, M_{,}\right.$) be a complete fuzzy metric space.Then continuous self-mappings $\mathrm{S}$ and $\mathrm{T}$ of $\mathrm{X}$ have a common fixed point in $\mathrm{X}$ if and only if there exites a self mapping $\mathrm{P}$ of $\mathrm{X}$ such that the following conditions are satisfied

(i) $\mathrm{PX} \subset \mathrm{TX} \cap \mathrm{SX}$

(ii) The pairs $\{\mathrm{P}, \mathrm{S}\}$ and $\{\mathrm{P}, \mathrm{T}\}$ are weakly compatible,

(iii) There exists a point $\mathrm{q \epsilon}(0,1)$ such that for all $\mathrm{x}, \mathrm{y} \epsilon \mathrm{X}$ and $\mathrm{t}>0$

$$
\mathrm{M}(\mathrm{Px}, \mathrm{Py}, \mathrm{qt}) \geq \mathrm{M}(\mathrm{Sx}, \mathrm{Ty}, \mathrm{t}) * \mathrm{M}(\mathrm{Sx}, \mathrm{Px}, \mathrm{t}) * \mathrm{M}(\mathrm{Py}, \mathrm{Ty}, \mathrm{t}) * \mathrm{M}(\mathrm{Px}, \mathrm{Ty}, \mathrm{t}) * \mathrm{M}(\mathrm{Py}, \mathrm{Sx}, \mathrm{t})
$$

Then P,S and T havea unique common fixed point.

Proof: Since compatible implies ows, the result follows from Theorem 3.4

Theorem 3.8 Let $(\mathrm{X}, \mathrm{M}, *)$ be a complete fuzzy metric space and let $\mathrm{P}$ and $\mathrm{R}$ be self-mappings of $\mathrm{X}$. Let the $\mathrm{P}$ and $\mathrm{R}$ areowc.If there exists $\mathrm{q} \epsilon(0,1)$ for all $\mathrm{x}, \mathrm{y \epsilon} \mathrm{X}$ and $\mathrm{t}>0$

$$
\mathrm{M}(\mathrm{Sx}, \mathrm{Sy}, \mathrm{qt}) \geq \alpha \mathrm{M}(\mathrm{Px}, \mathrm{Py}, \mathrm{t})+\beta \min \{\mathrm{M}(\mathrm{Px}, \mathrm{Py}, \mathrm{t}), \mathrm{M}(\mathrm{Sx}, \mathrm{Px}, \mathrm{t}), \mathrm{M}(\mathrm{Sy}, \mathrm{Py}, \mathrm{t}), \mathrm{M}(\mathrm{Sx}, \mathrm{Py}, \mathrm{t})\}
$$

For all $\mathrm{x}, \mathrm{y} \in \mathrm{X}$ where $\alpha, \beta>0, \alpha+\beta>1$. Then $\mathrm{P}$ and $\mathrm{S}$ have a unique common fixed point.

Proof: Let the pairs $\{\mathrm{P}, \mathrm{S}\}$ be owc, so there are points $\mathrm{x} \in \mathrm{X}$ such that $\mathrm{Px}=\mathrm{Sx}$. Suppose that exist another point $\mathrm{y}$ $\epsilon \mathrm{X}$ for whichPy $=\mathrm{Sy}$. We claim that $\mathrm{Sx}=\mathrm{Sy}$. By inequality (8)

We have

$$
\begin{aligned}
& \mathrm{M}(\mathrm{Sx}, \mathrm{Sy}, \mathrm{qt}) \geq \alpha \mathrm{M}(\mathrm{Px}, \mathrm{Py}, \mathrm{t})+\beta \min \{\mathrm{M}(\mathrm{Px}, \mathrm{Py}, \mathrm{t}), \mathrm{M}(\mathrm{Sx}, \mathrm{Px}, \mathrm{t}), \mathrm{M}(\mathrm{Sy}, \mathrm{Py}, \mathrm{t}), \mathrm{M}(\mathrm{Sx}, \mathrm{Py}, \mathrm{t})\} \\
&=\alpha \mathrm{M}(\mathrm{Sx}, \mathrm{Sy}, \mathrm{t})+\beta \min \{\mathrm{M}(\mathrm{Sx}, \mathrm{Sy}, \mathrm{t}) \quad, \quad \mathrm{M}(\mathrm{Sx}, \mathrm{Sx}, \mathrm{t}), \quad \mathrm{M}(\mathrm{Sy}, \mathrm{Sy}, \mathrm{t}), \quad \mathrm{M}(\mathrm{Sx}, \mathrm{Sy}, \mathrm{t})\} \\
&=(\alpha+\beta) \mathrm{M}(\mathrm{S} x, \mathrm{Sy}, \mathrm{t})
\end{aligned}
$$

A contradiction, since $(\alpha+\beta)>1$. Therefore $S x=S y$. Therefore $P x=P y$ and $P x$ is unique.

From lemma2.8, $\mathrm{P}$ and $\mathrm{S}$ have a unique fixed point.

Acknowledgement: One of the author (Dr. R.K. B.) is thankful to MPCOST Bhopal for the project No 2556

\section{References}

[1]P.Balasubramaniam,S.Murlisankar,R.P.Pant,"Common fixed points of four mappings in a fuzzy metric spaces”,J.Fuzzy Math. 10(2) (2002), 379-384.

[2]A.George, P.Veeramani,"'On some results in fuzzy metric spaces”,Fuzzy Sets and Systems, 64 (1994), 395399.

[3]G.Jungck,"Compatible mappings and common fixed points (2)”,Internat.J.Math.Sci. (1988), 285-288.

[4]G.Jungck and B.E.Rhoades,"Fixed Point Theorems for Occasionally Weakly compatible Mappings",Fixed Point Theory, Volume 7, No. 2, 2006, 287-296.

[5]O.Kramosil and J.Michalek,"Fuzzy metric and statistical metric spaces",Kybernetika, 11 (1975), 326-334.

[6]B.Schweizer and A.Sklar,’Statistical metric spaces”,Pacific J. Math.10 (1960),313-334

[7]L.A.Zadeh, Fuzzy sets, Inform and Control 8 (1965), 338-353. 
This academic article was published by The International Institute for Science, Technology and Education (IISTE). The IISTE is a pioneer in the Open Access Publishing service based in the U.S. and Europe. The aim of the institute is Accelerating Global Knowledge Sharing.

More information about the publisher can be found in the IISTE's homepage: http://www.iiste.org

\section{CALL FOR PAPERS}

The IISTE is currently hosting more than 30 peer-reviewed academic journals and collaborating with academic institutions around the world. There's no deadline for submission. Prospective authors of IISTE journals can find the submission instruction on the following page: http://www.iiste.org/Journals/

The IISTE editorial team promises to the review and publish all the qualified submissions in a fast manner. All the journals articles are available online to the readers all over the world without financial, legal, or technical barriers other than those inseparable from gaining access to the internet itself. Printed version of the journals is also available upon request of readers and authors.

\section{IISTE Knowledge Sharing Partners}

EBSCO, Index Copernicus, Ulrich's Periodicals Directory, JournalTOCS, PKP Open Archives Harvester, Bielefeld Academic Search Engine, Elektronische Zeitschriftenbibliothek EZB, Open J-Gate, OCLC WorldCat, Universe Digtial Library, NewJour, Google Scholar

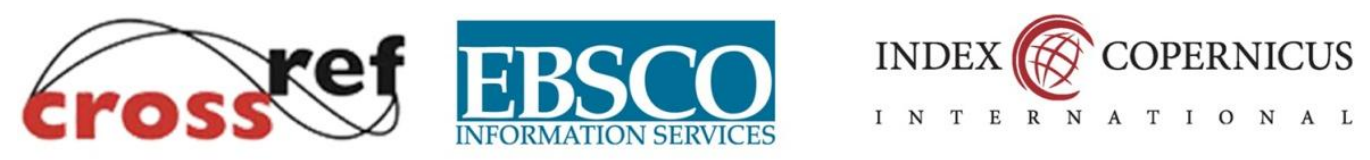

(O) ULRICHSWEB"

JournalTOCs

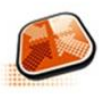

PKP | PUBLIC KNOWLEDGE PROJECT
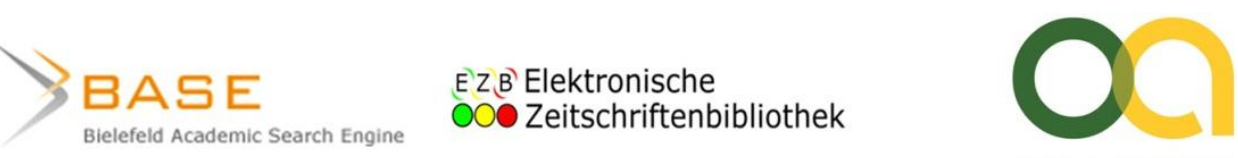

open access
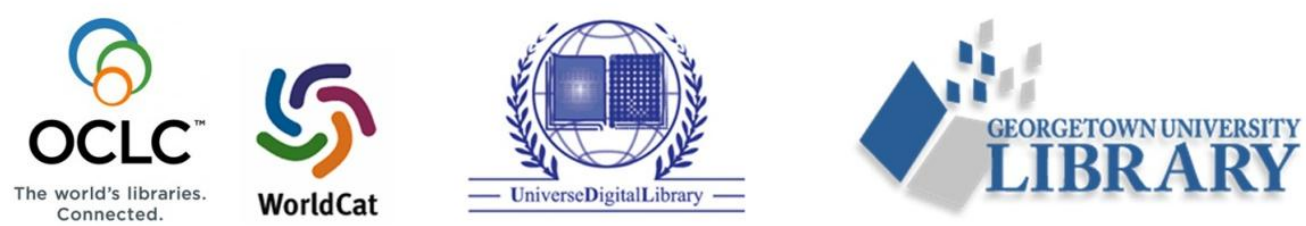